Article

\title{
Quasi-Global Evaluation of IMERG and GSMaP Precipitation Products over Land Using Gauge Observations
}

\author{
Hua Wang ${ }^{1,2}$ and Bin Yong ${ }^{1,3, *}$ \\ 1 School of Earth Sciences and Engineering, Hohai University, Nanjing 210098, China; wangh_df@163.com \\ 2 Zhejiang University of Finance \& Economics Dongfang College, Haining 314408, China \\ 3 State Key Laboratory of Hydrology-Water Resources and Hydraulic Engineering, Hohai University, \\ Nanjing 210098, China \\ * Correspondence: yongbin@hhu.edu.cn
}

Received: 30 October 2019; Accepted: 14 January 2020; Published: 15 January 2020

\begin{abstract}
Understanding the error distribution of satellite precipitation products is conducive to obtaining accurate precipitation data, which is a very important input parameter in hydrological models and climate models. The error characteristics of Integrated Multi-satellite Retrievals for Global Precipitation Measurement (IMERG) and Global Satellite Mapping of Precipitation (GSMaP) uncalibrated products on quasi-global land and six continents are evaluated, and the effects of latitude, elevation, and season on satellite precipitation product accuracy are analyzed. In order to be consistent with the Climate Prediction Center (CPC), the selected products are resampled at $0.5^{\circ}$ and daily resolutions from 1 January 2015 to 31 August 2018. We find out that (1) GSMaP performs worse than IMERG mainly due to systematic errors and poor performance at high latitudes; (2) overestimation is obvious in high latitude areas of the northern hemisphere and also in areas with low rainfall intensity; (3) IMERG and GSMaP show good performance in summer and poor performance in winter; (4) where elevation is lower than $1500 \mathrm{~m}$, the error metrics are highly correlated with the elevation; (5) the correlation coefficient is relatively high in areas with high rainfall, and the dispersion of satellite data and gauge data is also high. IMERG is a high-quality satellite precipitation product in the GPM era, but some uncertainties mentioned above are still worthy of attention by product developers and users.
\end{abstract}

Keywords: satellite precipitation; IMERG; GSMaP; evaluation

\section{Introduction}

Precipitation is a highly variable environmental parameter of which distribution varies a lot spatially and temporally. Accurate precipitation estimation on a global scale is helpful to understand hydrological cycle and the Earth's energy balance. Along with the development of satellite remote sensing technology, satellite precipitation products supplement the traditional rain gauge and radar rainfall measurement technology. It is of vital importance to observe precipitation data quickly with high temporal resolution in a global scale. In 1997, the Tropical Rainfall Measuring Mission (TRMM) initiated by the National Aeronautics and Space Administration (NASA) and the Japan Aerospace Exploration Agency (JAXA) covered all regions of the world between $60^{\circ} \mathrm{S}$ and $60^{\circ} \mathrm{N}$. The TRMM satellite carried the world's first satellite-borne precipitation radar (PR; Ku-band using $13.8 \mathrm{GHz}$ ) and a multichannel TRMM Microwave Imager (TMI; frequency range from 10.7 to $85.5 \mathrm{GHz}$ ). The two institutions cooperate to establish a calibration reference for microwave data from other constellation satellites. By combining infrared (IR) and passive microwaves (PMW), the researchers produced a variety of satellite precipitation products: TRMM Multi-satellite Precipitation Analysis (TMPA) [1], Climate Prediction Center morhing technique (CMORPH) [2,3], Precipitation Estimates from Remotely 
Sensed Information Using Artificial Neural Networks (PERSIANN) [4,5], and Global Satellite Mapping of Precipitation (GSMaP) [6].

With the success of TRMM, NASA and JAXA launched the next precipitation mission Global Precipitation Measurement (GPM). The GPM Core Observation carries a Ka/Ku-band dual-frequency precipitation radar (DPR) operates at $\mathrm{Ku}(13.6 \mathrm{GHz})$ and $\mathrm{Ka}(35.5 \mathrm{GHz})$ bands, and a GPM Microwave Imager (GMI) with a frequency ranges from 10 to $183.3 \mathrm{GHz}$ [7]. The upgraded DPR and GMI improved the detection of low precipitation rates $\left(<0.5 \mathrm{~mm} \mathrm{~h}^{-1}\right)$ and solid precipitation [8]. The non-sun-synchronous orbital inclination of the GPM core satellite has been increased from $35^{\circ}$ to $65^{\circ}$, and the altitude is $407 \mathrm{~km}$, which increased the monitoring range of more climatic zones and improved the precipitation estimation in the high latitude areas of the mainland. By incorporating the benefits of PERSIANN, TMPA, CMORPH, and other algorithms, GPM aims to provide the best precipitation products [9].

At present, the GPM program mainly includes two major precipitation products, namely Integrated Multi-satellite Retrievals for GPM (IMERG) developed by NASA and GPM-GSMaP developed by JAXA. Ushio et al. (2009) [10], who proved the effectiveness of the Kalman filter method and compared the GSMaP_MVK product with gauge data collected by the Automated Meteorological Data Acquisition System (AMeDAS) near Japan, found that GSMaP_MVK matches well with the AMeDAS and tends to underestimate large precipitation values. GSMaP_MVK products are also found to be comparable to COMORPH and 3B42RT (The near-real-time product of TMPA) products; Tian et al. (2010) [11] found that GSMaP has a better ability to capture the spatial distribution of summer precipitation, and its estimation of the total precipitation in the eastern area of the United States is better than that in the western are; Guo et al. (2017) [12] evaluated four different satellite precipitation products' (3B42, CMORPH, GSMaP, and PERSIANN) ability to capture the precipitation over central Asia, and found that the gauge-calibrated GSMaP performs better than others; and Prakash et al. (2016) [13] found that the consistency of IMERG and ground-based observations is better than that of TMPA, IMERG's estimation of precipitation in the southwest monsoon season shows notable improvements over TMPA in obtaining heavy rainfall over India, and IMERG helps to optimize the simulation of hydrological extreme values. They also found that IMERG performs similarly to TMPA in terms of the volume of hit, missed, and false precipitation, and that IMERG underestimates the frequency of heavy rainfall in parts of northeast India; Tang et al. (2016) [14] compared the TMPA and IMERG in southeast China and concluded that the Day 1 IMERG product can adequately substitute TMPA products both statistically and hydrologically; and Khan et al. (2018) [15] found that climatic zone-specific error characterization model is necessary to estimate uncertainties associated with the IMERG products. GSMaP's performance is better than TMPA's over a monsoon dominated region [16], the evaluation index reflects GSMaP_Gau and GSMaP_NRT in China's performance is better than GSMaP_MVK [17]. Satellite precipitation estimation is highly uncertain in areas where terrain is the main factor affecting precipitation [16]. GSMaP_MVK has not been fully detected in light rainfall events ( $<5 \mathrm{~mm} /$ day $)$ in China [17]. GSMaP_MVK showed underestimated rainfall days over sparsely-gauged African river basins [18]. GSMaP shows that rainfall is underestimated in winter and overestimated in summer. The overestimation in summer is mainly due to heavy precipitation events $[11,18]$. The overestimation of precipitation by GSMaP was relatively large, while the overestimation and underestimation of precipitation by IMERG were relatively small over Ardabil Province, Iran [19]. IMERG's monthly product captures major heavy rainfall over the northern and southern hemispheres [20]. IMERG shows that the error over land is greater than the error over sea, and the 6-h data performs better than the 3-h data at high latitude [21]. IMERG's ability to monitor rainfall events decreases with increasing rainfall intensity in Ethiopia [22]. The overall performance of IMERG in the amazon basin of South America is better than that of TRMM and has a good hydrologic application prospect [23-26]. Most of the existing literature covers small scales, such as city, province, country, and river basin. There are few studies on the global performance of satellite precipitation estimates, especially uncalibrated data from IMERG and GSMaP. We believe that the analysis of uncalibrated products can help developers and users better understand the error sources of satellite precipitation products. 
We study the accuracy of uncalibrated products in this paper, which is helpful to explore the error source of satellite products. Better accuracy can be obtained by using gauge data to calibrate high precision uncalibrated data. IMERG is a set of high-resolution satellite precipitation data that is currently being promoted by the global precipitation program; although it is highly expected, its inversion algorithm is not completely stable yet and is still under development. Our research focuses on the uncalibrated data of the two most mainstream satellite precipitation products in the GPM era, and is aimed at analyzing their error performance in the near global scale from the aspects of latitude, season, and elevation, as well as comparative analysis of six continents. The results of this study will help data producers further understand the error sources of satellite products, provide important scientific references for the follow-up research and development of the precipitation inversion algorithm of GPM satellite, and provide users better guidance to choose appropriate products. This paper is organized as follows: in Section 2, the data and the metrics for comparing satellite products against gauge data are introduced; in Section 3, the focus is the results and discussion; in Section 4, a brief summary and conclusions are given.

\section{Data and Methods}

\subsection{Data}

GSMaP provides three sets of mainstream types of satellite precipitation data based on different sensor input sources and algorithms, namely near-real-time product GSMaP_NRT, standard research product GSMaP_MVK, and gauge-calibrated product GSMaP_Gauge. The original instantaneous precipitation rate is estimated by a variety of passive microwave (PMW) sensors, including GPM Microwave Imager (GMI), advanced microwave scanning radiometer 2 (AMSR2), TRMM Microwave Imager (TMI), special sensor microwave imager/sounder (SSMIS), advanced microwave sounding unit-A (AMSU-A), and microwave humidity sounder (MHS) [27]. GSMaP_NRT uses less PMW input streams and a forward-only cloud advection scheme [28]. GSMaP_MVK uses a Kalman filter method [10], which includes almost all available satellite-borne precipitation related sensors, and includes two-way (forward and backward) morphing techniques to determine rain areas from IR images [2]. GSMaP_Gauge is a gauge-calibrated version based on current GSMaP_MVK and the global precipitation data from the Climate Prediction Center (CPC) [29]. The GSMaP product was updated to product version 7 in 2017. GSMaP_MVK version 7 $\left(0.1^{\circ} / 1 \mathrm{~h}\right.$, Global $\left.60^{\circ} \mathrm{N}-60^{\circ} \mathrm{S}\right)$ was used in this paper (https://www.gportal.jaxa.jp). The GSMaP project aims to generate high-precision and high-resolution global precipitation products through the precipitation retrieval algorithm of reliable physical models $[10,30]$.

Since 2014, IMERG has released four official versions: IMERG-V03, IMERG-V04, IMERG-V05, and IMERG-V06, and provides three different precipitation products, including near-real-time product early run (latency $\approx 6 \mathrm{~h}$ ), late run (latency $\approx 8 \mathrm{~h}$ ), and the research-grade product final run (latency $\approx 4$ months) [20]. In the early run, only the forward direction of the cloud motion vector propagation algorithm was adopted, and the late run added the backward morphing based on this. In processing of the final run, more sensor data sources were introduced on the basis of the late run. In addition, in early run and late run, only the monthly climate method was used, while actual gauge data were not introduced; in the final run, the monthly data of the Global Precipitation Climatology Centre (GPCC) was introduced. Rainfall estimates in IMERG, initially retrieved by the PMW sensors through the Goddard Profiling Algorithm-Version 2014 (GPROF 2014) algorithms, are combined and inter-calibrated with CMORPH, TMPA, and PERSIANN [23]. IMERG's half-hourly data contains precipitationCal, precipitationUncal, randomError, HQprecipitation, HQprecipSource, HQobservationTime, IRprecipitation, IRkalmanFilterWeight, probabilityLiquidPrecipitation, and PrecipitationQualityIndex. We analyzed the precipitationUncal data, which is IMERG late run V05 $\left(0.1^{\circ} / 0.5 \mathrm{~h}\right.$, Global $\left.60^{\circ} \mathrm{N}-60^{\circ} \mathrm{S}\right)$ (http://pmm.nasa.gov/dataaccess/downloads/gpm). Although IMERG V5 is not the latest version, its performance in various situations is not very clear.

The gauge-based analysis of daily precipitation data in this study was produced by the National Oceanic and Atmospheric Administration's (NOAA's) Climate Prediction Center (CPC; ftp://ftp.cpc.ncep. 
noaa.gov/precip/CPC_UNI_PRCP/). This dataset employs an optimal interpolation (OI) technique to reproject gauge reports over CONUS to a 0.258 grid. The OI-based interpolation has been shown to have higher correlation with individual gauge measurements than other techniques [31]. CPC utilizes optimal interpolation objective analysis technique and combines multi-source data, including Global Telecommunication System (GTS), Cooperative Observer Network (COOP), and other national and international agencies to form a unified, high-precision precipitation product, which has been widely used [14,32-34]. The CPC uses gauge-based precipitation data, so it is impossible to extend it to sparsely or ungauged regions [33]. Spatial and temporal resolution of the CPC is $0.5^{\circ} /$ day of the grid over the global domain. For different countries and regions, the starting time of the daily precipitation data of the CPC is inconsistent due to local measurements. In order to match the satellite precipitation with the CPC, the hourly scale of satellite precipitation data is resampling to the daily scale.

\subsection{Methods}

In order to study and analyze the systematic and random errors, a series of evaluation metrics were used for comprehensive evaluation. The evaluation metrics include correlation coefficient (CC), root mean squared error (RMSE), mean error (ME), relative bias (BIAS), and critical success index (CSI). These metrics are defined as

$$
\begin{gathered}
\mathrm{CC}=\frac{\sum_{i=1}^{n}\left(G_{i}-\bar{G}\right)\left(S_{i}-\bar{S}\right)}{\sqrt{\sum_{i=1}^{n}\left(G_{i}-\bar{G}\right)^{2}} \times \sqrt{\sum_{i=1}^{n}\left(S_{i}-\bar{S}\right)^{2}}}, \\
\text { RMSE }=\sqrt{\frac{1}{n} \sum_{i=1}^{n}\left(S_{i}-G_{i}\right)^{2}}, \\
\text { ME }=\frac{1}{n} \sum_{i=1}^{n}\left(S_{i}-G_{i}\right), \\
\text { BIAS }=\frac{\sum_{i=1}^{n}\left(S_{i}-G_{i}\right)}{\sum_{i=1}^{n} G_{i}} \times 100 \%, \\
\operatorname{CSI}=\frac{H}{H+F+M^{\prime}},
\end{gathered}
$$

where $n$ is the total number of samples, and $S_{i}$ and $G_{i}$ represent satellite data and station data, respectively. $\bar{S}$ and $\bar{G}$ are the average value of satellite data and station data. $H$ represents observed precipitation correctly detected, that is, both ground measurements and satellite precipitation are greater than or equal to the threshold; $M$ represents observed precipitation not detected by the product, that is, ground precipitation is greater than or equal to the threshold and satellite precipitation is less than the threshold; $F$ represents precipitation detected but none observed, that is, ground precipitation is less than the threshold but satellite precipitation is greater than or equal to the threshold [35]. Perfect values for CC, RMSE, ME, BIAS, and CSI are 1, 0, 0, 0, and 1, respectively. We resampled the satellite data to $0.5^{\circ}$ by averaging the available data in each $0.5^{\circ} \times 0.5^{\circ}$ area and assigning it to the center of the grid [36], the main disadvantage is the uncertainty of resampling. In this method, the spatial coverage of the very light intensity observation is slightly expanded, and the intensity of heavy rainfall events is weakened. Therefore, we used $1 \mathrm{~mm} \mathrm{day}^{-1}$ to distinguish the difference between rainfall and non-rainfall. We used satellite data to match CPC to improve the data scale and the performance of satellite data; it may also eliminate the performance of data on short-time precipitation to some extent, but had no effect on the comparison of satellite products. Many researchers have adopted similar resampling methods and obtained good results [36-38]. The performance of IMERG and GSMaP satellite data was evaluated in a daily scale. To ensure that the data used in the calculation of various evaluation metrics all contain 
gauge data, only the grid containing at least one gauge for quantitative comparison at the grid scale was selected in this paper. The study period was from 1 January 2015 to 31 August 2018.

\section{Results and Discussion}

\subsection{General Description}

Figure 1 shows the spatial distributions of daily precipitation over the global land from 2015 to 2018 derived from CPC, GSMaP, and IMERG data sets. All products show similar spatial precipitation distribution characteristics. The precipitation areas related to the migration of the Inter-tropical Convergence Zone (ITCZ) over the eastern equatorial Pacific Ocean and Atlantic Ocean and the precipitation areas affected by the Asia summer monsoon show a heavy precipitation. The west coast of India has significant precipitation zones. In the middle latitudes of the northern hemisphere, the coast of the Asia Pacific region shows a large amount of precipitation. The Sahara Desert is dominated by a Subtropical high pressure belt and Northeasterly Trades from the continent, which makes it dry and rainless. Central Asia's deserts are far from the ocean and surrounded by plateaus which make it hard for moisture to approach. By comparing satellite-based data with gauge data, it is found that obvious data discrepancies are mainly distributed in central Africa, northwest China, central Australia and the continental United States, eastern Russia. Most of these areas show satellite estimates of precipitation higher than CPC.
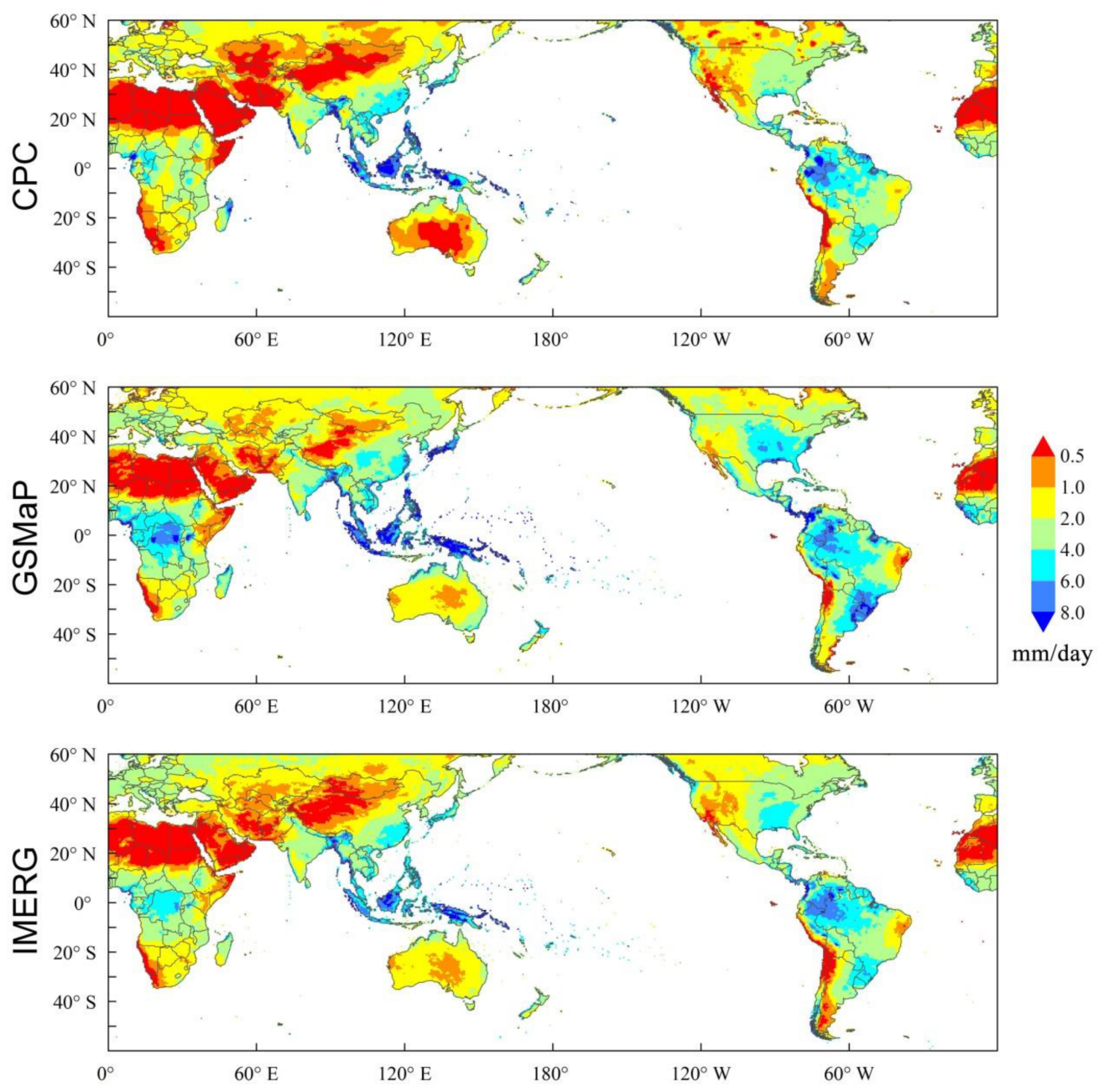

Figure 1. Spatial distributions of daily precipitation over the global land from 2015 to 2018 derived from Integrated Multi-satellite Retrievals for Global Precipitation Measurement (GPM; IMERG), Global Satellite Mapping of Precipitation (GSMaP), and Climate Prediction Center (CPC) (mm/day). 
All the statistical metrics indicate that the IMERG outperformed GSMaP with higher correlation and lower error (Figure 2). The scatter distribution shows IMERG have high CC (0.67) and low ME (0.21), low RMSE (6.38), and the points are clustered more closely to the 1:1 line than GSMaP, indicating that the systematic difference on rainfall estimation is greater in GSMaP than in IMERG. Both GSMaP and IMERG have positive relative bias and present overestimation, and GSMaP was more obvious. Overall, our evaluation indicates that the IMERG provides the best daily precipitation estimates and its systematic bias is $8 \%$.
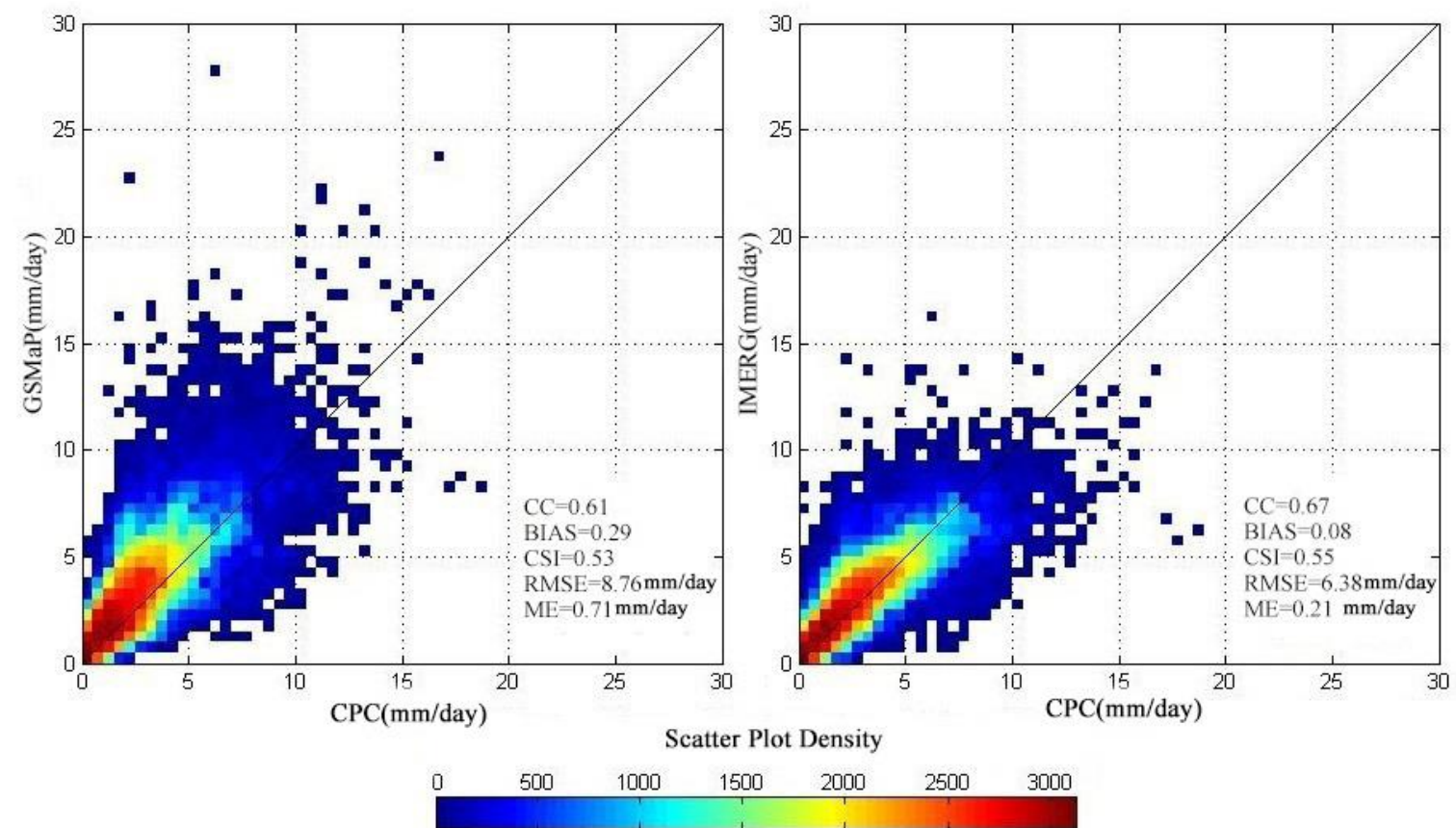

Figure 2. Two-dimensional scatterplots of daily precipitation for GSMaP and IMERG against CPC over quasi-global land.

Figure 3 describes the distribution of daily precipitation in latitude of GSMaP and IMERG against the CPC. It can be seen that the situation in the Northern Hemisphere is more complicated than that in the Southern Hemisphere, and the overestimation in the Northern Hemisphere is more obvious than that in the Southern Hemisphere. IMERG shows underestimation between $15^{\circ}$ and $20^{\circ} \mathrm{N}$, in other regions, GSMaP and IMERG show different degrees of overestimation. The curve of the IMERG product is closer to the benchmark data of the CPC, and GSMaP is overvalued on almost every continent in the world. IMERG showed a good consistency with the CPC, between $10^{\circ} \mathrm{N}$ and $10^{\circ} \mathrm{S}$, where there is high precipitation frequency and intensity. The consistency between IMERG and CPC in Asia is relatively high, indicating that IMERG has improved the overestimation of rainfall intensity in higher elevation areas [13]. With the increase of latitude, the overestimation of IMERG is more obvious in the northern hemisphere. The overestimation of IMERG is mainly in the cold season (December, January, and February) in North America, between $30^{\circ} \mathrm{N}$ and $40^{\circ} \mathrm{N}$, and is relatively serious in December and February. The overestimation of IMERG increased gradually from $30^{\circ} \mathrm{N}$ to $60^{\circ} \mathrm{N}$, and the overestimation of GSMaP between $40^{\circ}$ and $60^{\circ} \mathrm{N}$ was also significant. This is mainly because it is difficult for satellite precipitation products to accurately detect rainfall in high latitude areas [33]. In addition, satellite precipitation products have limited ability to capture precipitation in cold seasons when the ground is covered with snow and ice [28]. 


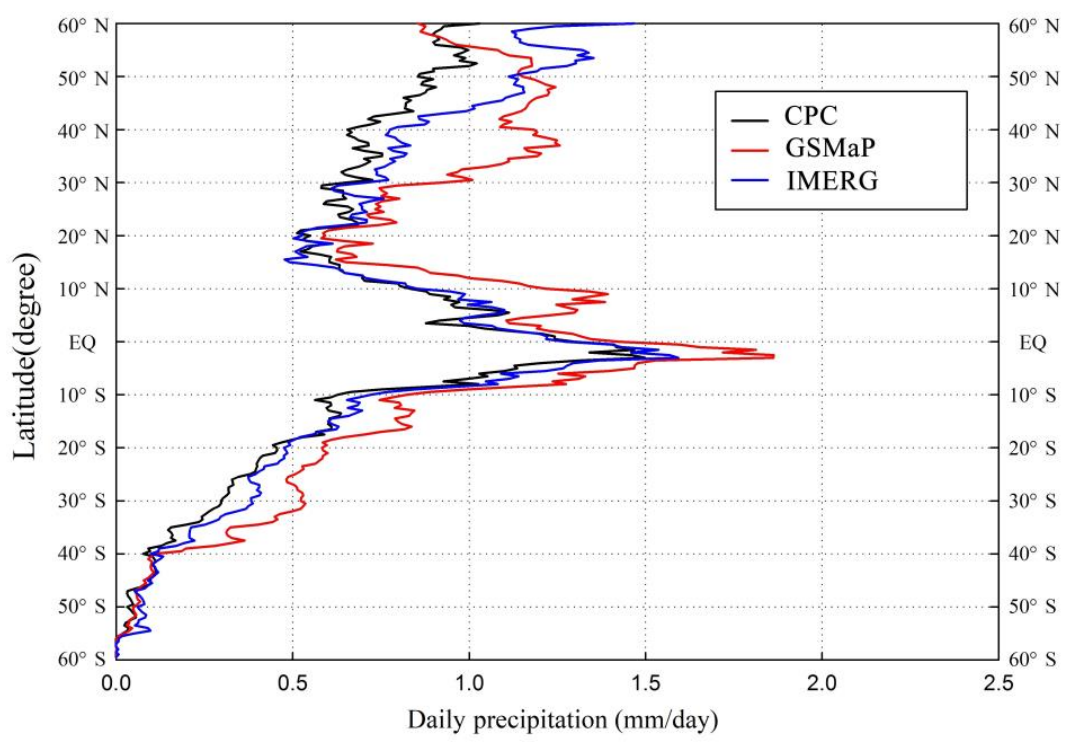

Figure 3. The distribution of daily precipitation in latitude of GSMaP and IMERG against CPC.

\subsection{Spatial Distribution of CC, BIAS, and CSI}

Figure 4 shows the spatial distributions of statistical metrics computed from the GSMaP and IMERG daily precipitation estimates. The distribution of CC, BIAS, and CSI reveal the spatial performance of GSMaP and IMERG, which is very important for the precipitation data quality in the water cycle research and give a clear indication of where the datasets are performing better or worse. CC $(C C<0.4)$, BIAS (BIAS > 3), and CSI (CSI < 0.4) reflect that the uncertainty of satellite precipitation data is mainly concentrated in North Africa $\left(20^{\circ} \mathrm{N}\right.$ to $\left.30^{\circ} \mathrm{N}\right)$, northwest China, and central Australia. The GSMaP and IMERG products have similar CC, BIAS, and CSI distributions over Africa, Southeast Asia, and South America. The IMERG demonstrates much improvement over GSMaP in the northwest Asia with higher CC and lower BIAS. Additionally, the IMERG did not significantly improve the metrics over North Africa $\left(20^{\circ} \mathrm{N}\right.$ to $\left.30^{\circ} \mathrm{N}\right)$ when compared to GSMaP, whereas the IMERG not only shows better precipitation estimates in terms of CC, but also improves BIAS over most areas in the northwest Asia.

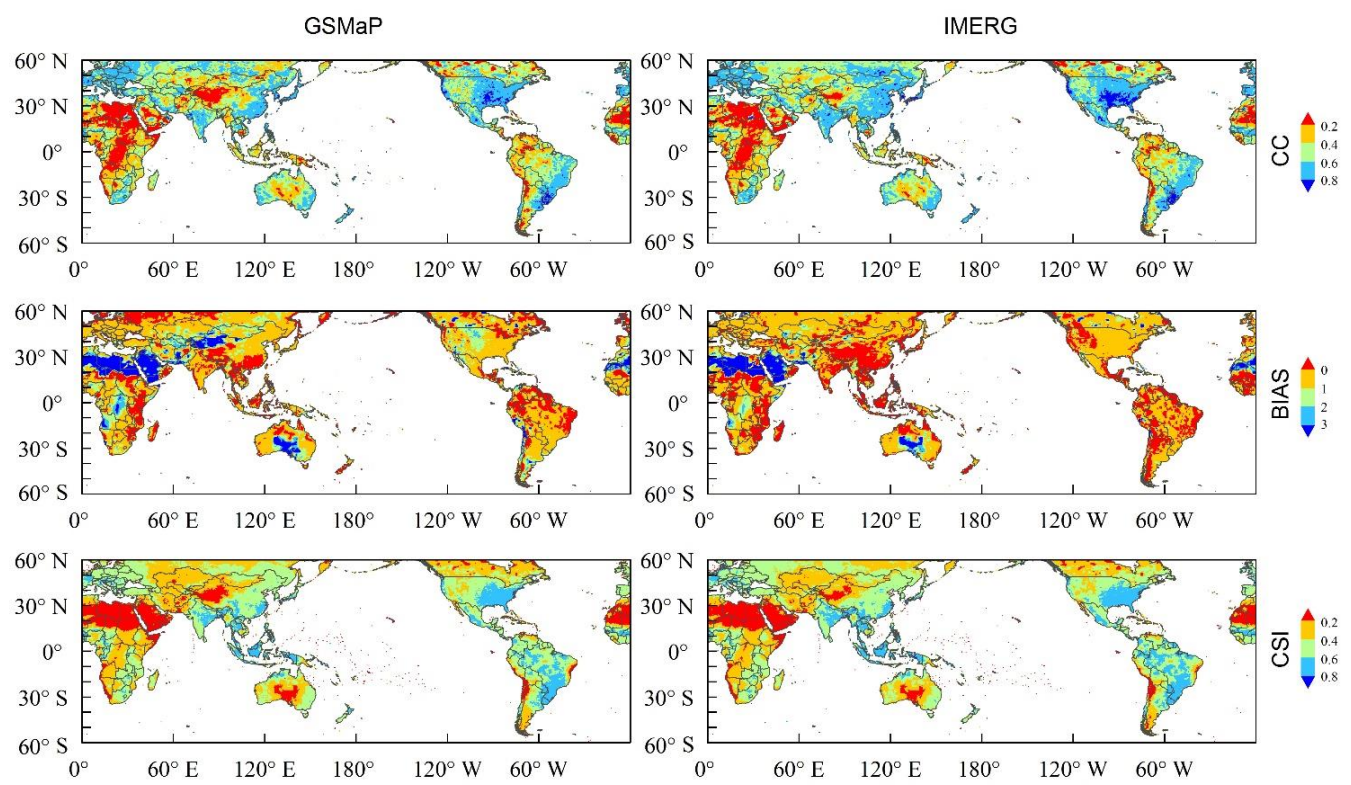

Figure 4. The spatial distributions of statistical metrics computed from the GSMaP and IMERG daily precipitation estimates over the global land: correlation coefficient (CC), relative bias (BIAS), and critical success index (CSI). 


\subsection{Seasonal Precipitation Analysis}

Figure 5 shows the distribution of the CC, BIAS, and CSI in different seasons over the quasi-global $\left(60^{\circ} \mathrm{N}-60^{\circ} \mathrm{S}\right)$ land. The distribution of the CC, BIAS, and CSI is obviously related to seasonality, especially in the northern hemisphere $(\mathrm{NH})$. These statistical results illustrate that the IMERG performs better than GSMaP does over quasi-global $\left(60^{\circ} \mathrm{N}-60^{\circ} \mathrm{S}\right)$ during the study period. The distribution rules of the three metrics in June, July, August (JJA) and December, January, February (DJF) are quite different. In the northern hemisphere, the indicators showed that the satellite product had a small error in summer and a strong consistency with the CPC, and its performance was better than that in winter. As per the distribution of BIAS, GSMaP shows negative biases from $40^{\circ} \mathrm{N}$ to $60^{\circ} \mathrm{N}$, mainly affected by winter snow, which have been improved in IMERG. The negative bias over southeast China and the west coast of India were also likely the result of heavy rainfall from the Asia summer monsoon [39] and multi-scale interactions of monsoon flow and orography [13]. The Sahara Desert region of northern Africa is exceptionally overestimated, mainly because precipitation is very scarce. In the southern hemisphere, the three metrics show better performance during the DJF period. Overestimations exist in lake west Victoria, southern Congo, and Angola, where the climates are tropical rainforest climate and tropical grassland climate, and it happens to be the rainy season in central Africa in the JJA period.

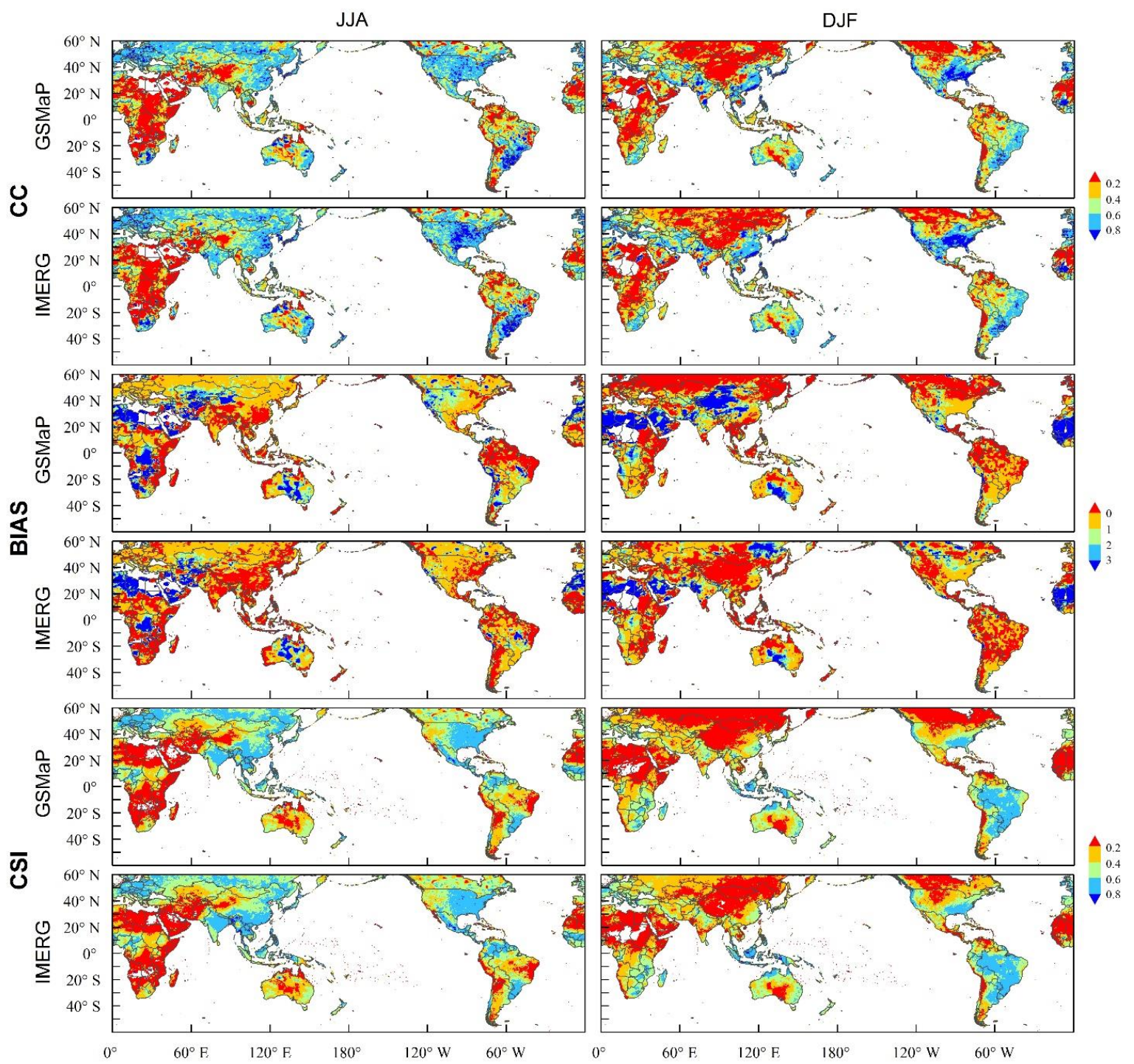

Figure 5. The distribution of the CC, BIAS, and CSI in different seasons (MAM: March, April, May; JJA: June, July, August; SON: September, October, November; DJF: December, January, and February). 
Tables 1 and 2 show that IMERG and GSMaP have a good performance in summer and a poor performance in winter in both the northern and southern hemispheres. In terms of the performance of GSMaP in the northern hemisphere, the CC (0.64), RMSE (7.63), ME (0.52), BIAS (0.20), and CSI (0.60) all achieved their optimal values in summer, and CC (0.62), RMSE (9.90), and CSI (0.39) achieved the worst results in winter. The characteristics of the error index in the southern hemisphere are basically similar to those in the northern hemisphere. It is worth noting that IMERG appears to perform better in autumn than in summer and winter in the southern hemisphere. Compared with GSMaP, the correlation between IMERG and CPC is better, with a smaller degree of dispersion, smaller average error, smaller deviation, and stronger ability to accurately capture actual precipitation events.

Table 1. Summary of error metrics for seasonal precipitation in the northern hemisphere.

\begin{tabular}{|c|c|c|c|c|c|}
\hline Error Metrics & Product & Spring (MAM) & Summer (JJA) & Autumn (SON) & Winter (DJF) \\
\hline \multirow{2}{*}{$\mathrm{CC}$} & GSMaP & 0.63 & 0.64 & 0.64 & 0.62 \\
\hline & IMERG & 0.68 & 0.69 & 0.71 & 0.59 \\
\hline \multirow{2}{*}{ RMSE } & GSMaP & 9.08 & 7.63 & 8.39 & 9.90 \\
\hline & IMERG & 5.78 & 6.63 & 6.26 & 11.03 \\
\hline \multirow{2}{*}{$\mathrm{ME}$} & GSMaP & 1.11 & 0.52 & 0.59 & 0.66 \\
\hline & IMERG & 0.36 & 0.10 & 0.15 & 0.78 \\
\hline \multirow{2}{*}{ BIAS } & GSMaP & 0.52 & 0.20 & 0.24 & 0.29 \\
\hline & IMERG & 0.17 & 0.03 & 0.06 & 0.18 \\
\hline \multirow{2}{*}{ CSI } & GSMaP & 0.53 & 0.60 & 0.54 & 0.39 \\
\hline & IMERG & 0.54 & 0.61 & 0.56 & 0.61 \\
\hline
\end{tabular}

Table 2. Summary of error metrics for seasonal precipitation in the southern hemisphere.

\begin{tabular}{|c|c|c|c|c|c|}
\hline Error Metrics & Product & Spring (SON) & Summer (DJF) & Autumn (MAM) & Winter (JJA) \\
\hline \multirow{2}{*}{$\mathrm{CC}$} & GSMaP & 0.62 & 0.64 & 0.61 & 0.59 \\
\hline & IMERG & 0.66 & 0.64 & 0.66 & 0.62 \\
\hline \multirow{2}{*}{ RMSE } & GSMaP & 9.08 & 6.90 & 10.03 & 7.65 \\
\hline & IMERG & 6.26 & 8.52 & 7.45 & 5.65 \\
\hline \multirow{2}{*}{$\mathrm{ME}$} & GSMaP & 1.04 & 0.16 & 0.59 & 0.41 \\
\hline & IMERG & 0.08 & -0.14 & 0.004 & -0.02 \\
\hline \multirow{2}{*}{ BIAS } & GSMaP & 0.44 & 0.09 & 0.19 & 0.26 \\
\hline & IMERG & 0.04 & -0.03 & 0.002 & -0.01 \\
\hline \multirow{2}{*}{ CSI } & GSMaP & 0.53 & 0.39 & 0.54 & 0.43 \\
\hline & IMERG & 0.53 & 0.61 & 0.55 & 0.44 \\
\hline
\end{tabular}

Light rainfall will be missed and total rainfall will be underestimated by IR rainfall algorithms in the high-altitude regions because of the influence of cloud warm temperatures [34,40,41]. Since there was no rain in parts of Africa during the study period, invalid values appear in Figure 5. GSMaP and IMERG performed poorly in areas with higher altitudes (Tibetan plateau and western North America), regardless of the season. This implies that the precision of satellite precipitation products may be dependent on elevation.

There are limitations to obtaining global quantitative precipitation estimates in high-elevation areas [28,32]. Using thermal IR to distinguish raining and non-raining clouds at high elevation may not be accurate, as there are relatively warm clouds at high-elevation regions [40,41]. In order to study the dependency of the error components on elevation, we divide the elevation into four sections. The correlation between error index and elevation is calculated under different terrains, as shown in Table 3. With reference to Table 1, it is found that where the elevation was below $1500 \mathrm{~m}$, the error metrics were highly correlated with the elevation. Where elevation is above $1500 \mathrm{~m}$, the correlation between error metrics and elevation is very small. Where the elevation is less than $400 \mathrm{~m}$, the error index shows that the performance of the satellite becomes worse as the elevation increases. Where the elevation is above $400 \mathrm{~m}$ and below $1500 \mathrm{~m}$, 
the error index shows that the performance of satellite products is better with the increase of elevation. In addition, the error metrics of IMERG is more correlated with elevation than GSMaP.

Table 3. Correlation between elevation and error metrics.

\begin{tabular}{cccccc}
\hline Error Metrics & Product & $\mathbf{< 4 0 0 ~} \mathbf{~}$ & $\mathbf{4 0 0 - 1 5 0 0 ~} \mathbf{~}$ & $\mathbf{1 5 0 0 - 2 5 0 0 ~} \mathbf{~}$ & $\mathbf{2 5 0 0} \mathbf{~}$ \\
\hline \multirow{2}{*}{ CC } & GSMaP & -0.71 & 0.56 & -0.07 & -0.17 \\
& IMERG & -0.88 & 0.74 & -0.06 & -0.05 \\
BIAS & GSMaP & 0.68 & -0.57 & 0.18 & -0.02 \\
& IMERG & 0.74 & -0.58 & 0.15 & -0.18 \\
\multirow{2}{*}{ CSI } & GSMaP & -0.73 & 0.79 & -0.22 & -0.06 \\
& IMERG & -0.86 & 0.82 & 0.05 & 0.00 \\
ME & GSMaP & -0.4 & -0.28 & 0.01 & -0.01 \\
& IMERG & -0.81 & -0.31 & -0.09 & -0.30 \\
\multirow{2}{*}{ RMSE } & GSMaP & -0.41 & -0.37 & 0.26 & -0.08 \\
& IMERG & -0.71 & -0.56 & -0.03 & -0.55 \\
\hline
\end{tabular}

Table 4 is the comparison chart of the error metrics of GSMaP and IMERG in six continents of the world. North and South America are regions with large annual average precipitation, and the correlation coefficient (CC) between satellite precipitation products and CPC is relatively high, which is similar to the previous research conclusion [42], that is, rainy regions have high correlation coefficients. The low correlation coefficient in Africa and Oceania may be due to highly non-linear rain-runoff response and the high transmission losses. The dispersion of satellite data and gauge data is also high in areas with high rainfall. For example, the RMSE values in Europe and Africa are small, while those in South America are large. Europe has the largest ME, which is related to winter precipitation type. According to ME and BIAS, the uncertainty of satellite products increases with the increase of latitude. Combining these four metrics, the accuracy of satellite precipitation products is highest in South America and lowest in Europe, which is related to the larger precipitation in South America and the limited ability of satellite precipitation products to catch snow in Europe in winter.

Table 4. Summary of error metrics for the different continents.

\begin{tabular}{ccccccccc}
\hline $\begin{array}{c}\text { Error } \\
\text { Metrics }\end{array}$ & Product & ALL & Asia & $\begin{array}{c}\text { North } \\
\text { America }\end{array}$ & Europe & $\begin{array}{c}\text { South } \\
\text { America }\end{array}$ & Africa & Oceania \\
\hline \multirow{2}{*}{ CC } & GSMaP & 0.61 & 0.58 & 0.69 & 0.61 & 0.64 & 0.51 & 0.61 \\
& IMERG & 0.67 & 0.68 & 0.73 & 0.62 & 0.68 & 0.56 & 0.66 \\
RMSE & GSMaP & 8.76 & 9.21 & 8.87 & 5.57 & 9.40 & 7.95 & 8.36 \\
& IMERG & 6.38 & 6.48 & 6.11 & 5.18 & 6.94 & 5.95 & 5.89 \\
ME & GSMaP & 0.71 & 0.52 & 1.10 & 0.28 & 0.70 & 0.71 & 0.75 \\
& IMERG & 0.21 & -0.09 & 0.41 & 0.49 & 0.04 & 0.06 & 0.12 \\
BIAS & GSMaP & 0.29 & 0.20 & 0.47 & 0.15 & 0.22 & 0.41 & 0.37 \\
& IMERG & 0.08 & -0.03 & 0.17 & 0.26 & 0.01 & 0.04 & 0.06 \\
\hline
\end{tabular}

The number of gauge stations in North America, Asia, South America, Europe, Oceania, and Africa is $3839,1945,1450,1370,1056$, and 713 respectively. Figure 6 is the frequency of rainfall measurements; we can see that the performance of satellite precipitation products may be better in places with more gauge stations and higher frequency of rainfall measurements. For example, the CC of North America is the highest among the six regions, and the CC of GSMaP and IMERG are respectively 0.69 and 0.73. IMERG's ME (0.04) and BIAS (0.01) were the smallest in South America. 


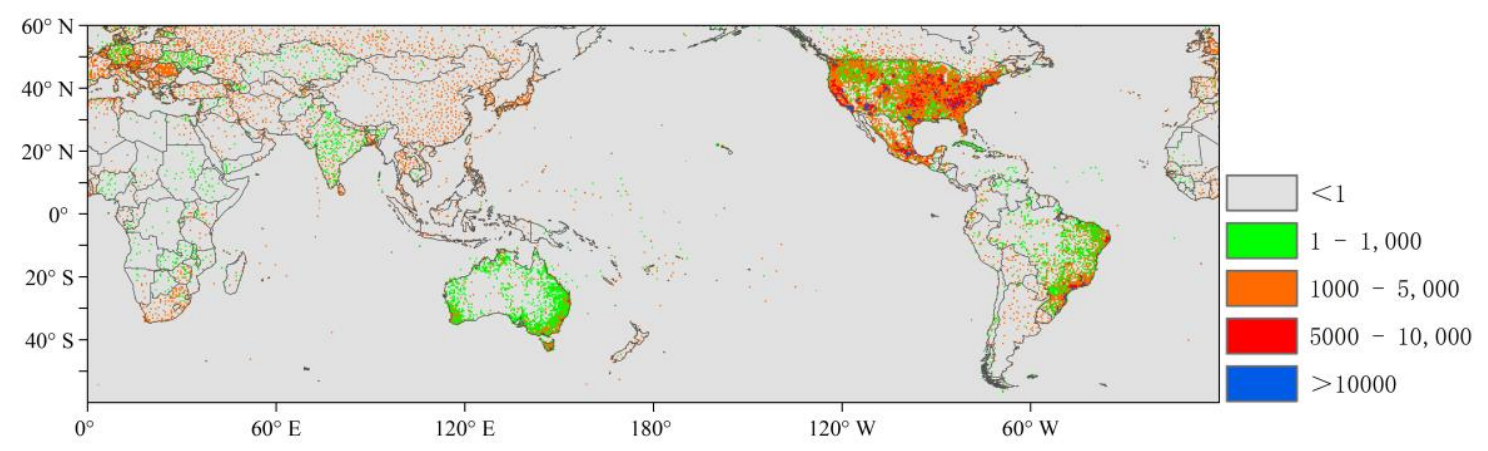

Figure 6. The frequency of rainfall measurements of CPC during the study period.

\subsection{Probability Distribution Function (PDF) Analysis}

The intensity distributions of daily precipitation amounts are showed in Figure 7. In this study, rainfall intensity is taken as the interval to calculate the relative contribution rate of each error component to the total error. The horizontal axis in Figure 7 represents the interval distribution of rainfall intensity exceeding the precipitation event judgment threshold ( $1 \mathrm{~mm} /$ day), and the interval is divided by the form of exponential distribution. The precipitation on the vertical axis represents the average daily cumulative precipitation value of the grid in each rain-intensity interval. Based on the error component decomposition model proposed by Tian (2010) [11], this study took rainfall intensity as the interval to calculate the relative contribution rate of each error component to the total error. Since the probability distribution of rain intensity of precipitation events is closer to lognormal, this paper first divides the interval range of rain intensity into $\mathrm{N}+1$ continuous log scale intervals.

Compared with the gauge data, the two precipitation products have a better fit at moderate and low rainfall intensity. When the rainfall intensity is less than $16 \mathrm{~mm} /$ day, most regions and seasons are underestimated, especially in winter in Asia, North America, and Europe. When rainfall exceeded $16 \mathrm{~mm} /$ day, the overestimation is obvious, especially in MAM, JJA, and SON. In Figure 6, we found that there was a huge difference between satellite products and the CPC in Europe in December, January, and February. The peak of GSMaP was half of the peak of IMERG, and IMERG was significantly overestimated in the range of 8-128 mm/day. IMERG performed best in JJA, and the remaining three seasons showed consistent performance in low-rain-intensity regions and overestimation in high-rain-intensity regions (20.34-125.92 mm/day). In DJF, GSMaP shows an underestimated phenomenon in low-rain-intensity regions (1.9-14.12 mm/day). Except for the overestimated peak of $42.17 \mathrm{~mm} /$ day rainfall intensity in JJA, the overestimated peak of IMERG was $50.61 \mathrm{~mm} /$ day rainfall intensity at all other times. The positive bias in GSMaP is likely due to overestimation by the PMW-based land algorithms for strong convective events during the warm season [43].

From December to May of the following year, South America has a high precipitation frequency and a large amount of precipitation. From Figure 7(SA-a,SA-d), we can see that the satellite product curve is very similar to the CPC curve, which further indicates that the higher the rainfall is, the better the performance of satellite products will be. Compared with GSMaP, improvement in the low rainfall sensors in IMERG has improved low rainfall estimates in the cold season (winter and spring) in Europe and North America. However, IMERG still underestimated the intensity of low precipitation and overestimated the intensity of high precipitation in the cold season in Europe, which may be related to the poor quantitative capacity of the DPR algorithm for solid precipitation.

From the results (Table 4) of CC, ME, and BIAS in Europe, the performance of IMERG and GSMaP is similar, but Figure 7 shows that GSMaP is better than IMERG in Europe in the following cases: rain intensity in MAM is around $16 \mathrm{~mm} /$ day, rain intensity in JJA between 2 and $8 \mathrm{~mm} /$ day, rain intensity in SON between 16 and $128 \mathrm{~mm} /$ day, rain intensity in DJF between 16 and $128 \mathrm{~mm} /$ day. 

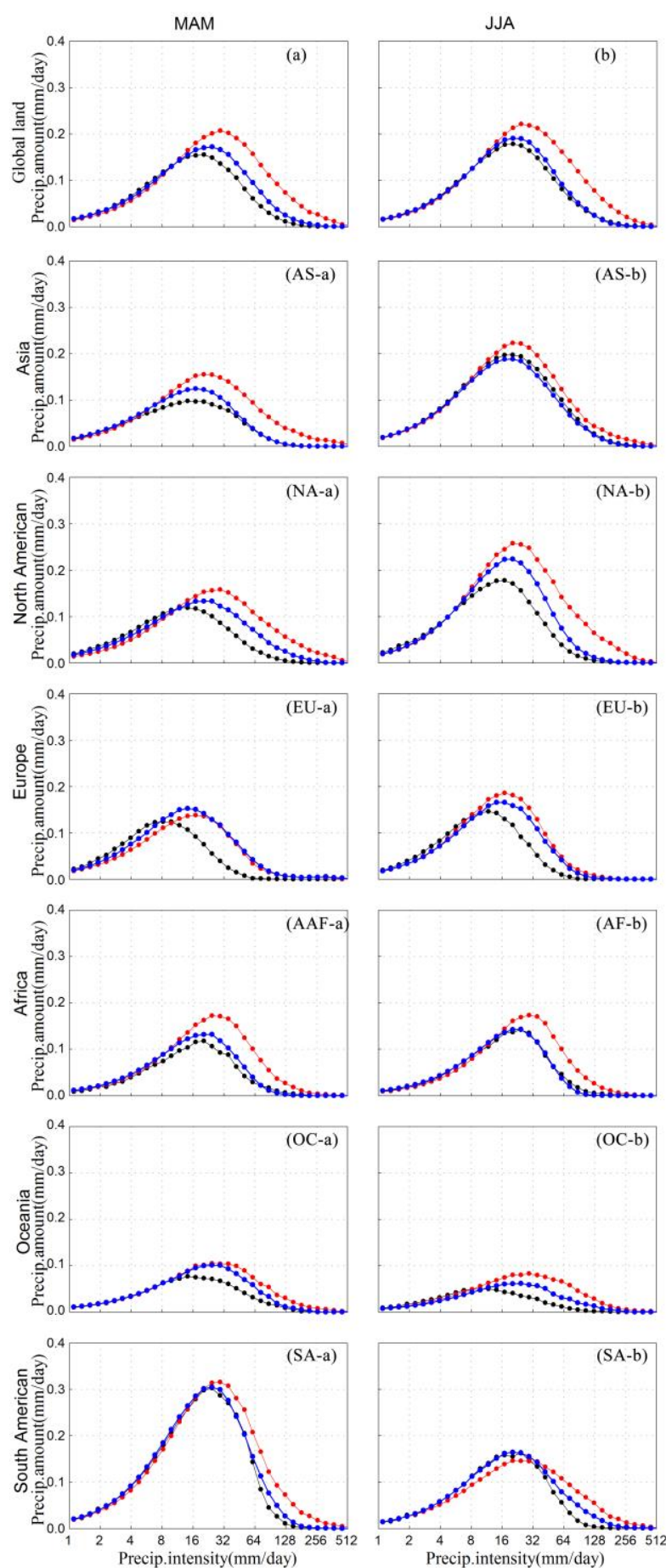

- $\mathrm{CPC}$
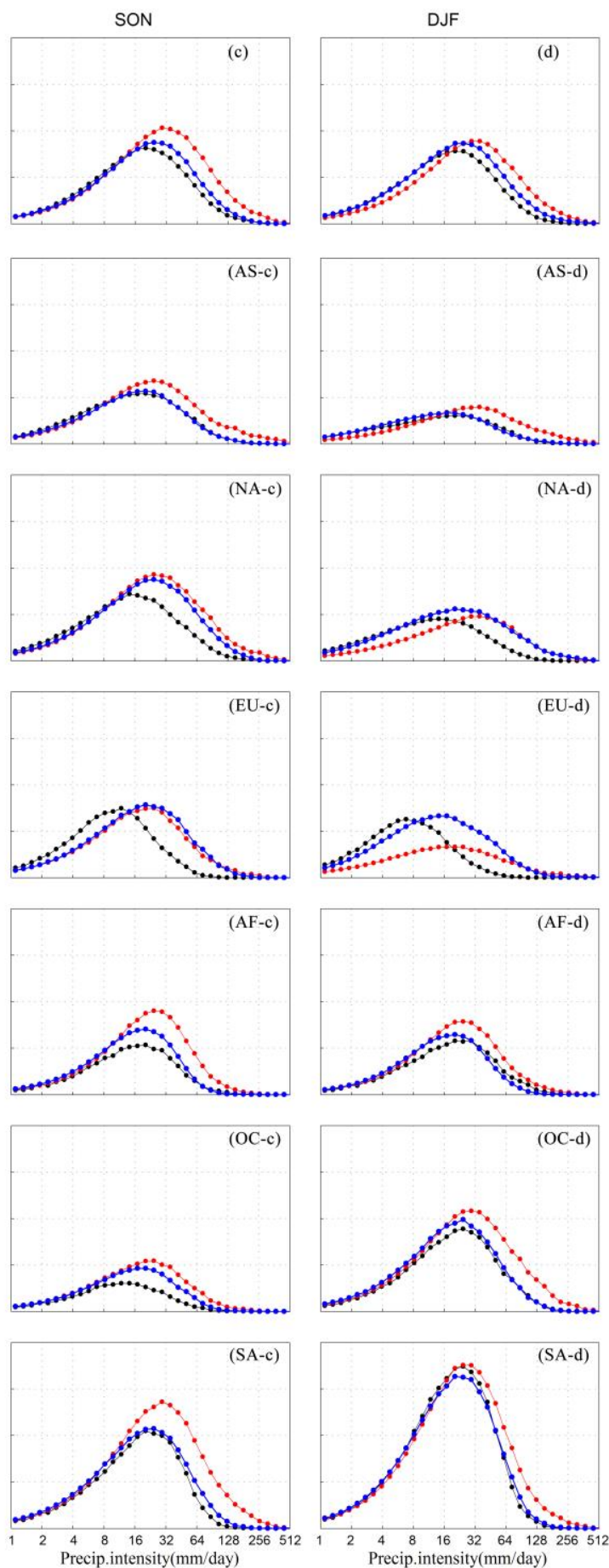

- IMERG

Figure 7. The distribution of CPC, GSMaP, and IMERG on the interval of daily precipitation intensity in different seasons.

\section{Conclusions}

High-resolution multi-satellite precipitation products are very important for hydrology and water resources research. In this paper, we studied the error performance of the pure satellite products of IMERG and GSMaP in the quasi-global continental region. The main findings of this study are as follows:

1. IMERG and GSMaP products were compared with the CPC data set on a daily scale from January 2015 to August 2018. The performance of two groups of products in the quasi-global and six continents was analyzed by calculating the error metrics. The major differences between satellite-based data and 
gauge data are mainly distributed in central Africa, northwest China, central Australia, continental United States, and eastern Russia. The scatter diagram shows that the systematic error of IMERG is smaller than that of GSMaP. The overestimation in the northern hemisphere is more obvious than in the Southern Hemisphere due to the complex topography and underlying surface features of the northern hemisphere. IMERG performed better when the frequency and intensity of precipitation was higher. With the increase of latitude, the overestimation of IMERG is more obvious in the northern hemisphere.

2. CC, BIAS, and CSI comprehensively reflect the satellite precipitation data uncertainty (CC $<0.4$, BIAS > 3, CSI < 0.4) mainly concentrated in north Africa $\left(20^{\circ} \mathrm{N}\right.$ to $\left.30^{\circ} \mathrm{N}\right)$, northwest of China, and central Australia. IMERG performance improved significantly over GSMaP, especially in northwest Asia, but not significantly in North Africa $\left(20^{\circ} \mathrm{N}\right.$ to $\left.30^{\circ} \mathrm{N}\right)$.

3. The performance of satellite products is significantly correlated with seasons, and the performance in summer is better than that in winter. The number of gauge stations also affects the result of error metrics. Areas with low precipitation, such as the Sahara region of northern Africa, are easily overestimated. The estimation of satellite precipitation in the area with elevation greater than $2500 \mathrm{~m}$ has significant limitations. Where elevation is lower than $1500 \mathrm{~m}$, the error index is obviously dependent on the elevation.

4. During the period of low rainfall intensity, satellite precipitation products had good consistency with gauge data. Judging by the PDF, when the precipitation frequency and precipitation amounts are larger, the satellite products are closer to reality. Although IMERG performs better in low rain intensity, there is still overestimation, which may be related to the poor quantitative capacity of the DPR algorithm for solid (snowfall) precipitation.

The analysis presented in this paper provides a reference for the evaluation of future satellite precipitation products and shows the potential in hydrologic applications. If users need to use GSMAP and IMERG data in hydrological and climate models, they should choose appropriate data according to the research area, accuracy requirements, and time range. The research can help data producers understand the disadvantages of their products. We find that the performance of the error index is related to the number of rain gauges. For areas with limited gauge stations, such as Africa and the Tibetan plateau, we need to find more suitable assessment methods. Future work will focus on developing methods for evaluating satellite precipitation products in areas with few gauge stations. The evaluation of satellite products in this paper does not go deep into the study of algorithms, and some of the analyses related to algorithms still have some uncertainty.

Author Contributions: H.W. collected the data, conducted the experiments and wrote the paper; B.Y. designed the study, supervised the research and revised the manuscript. All authors have read and agreed to the published version of the manuscript.

Funding: This work was sponsored by National Key Research and Development Program of China (2018YFA0605402), National Natural Science Foundation of China (91547101,515 91647203) and Natural Science Foundation of Jiangsu Province (BK20161502).

Acknowledgments: Thanks to data producers for providing available satellite precipitation data, such as the GPM science team at NASA and JAXA, and the Earth Observation Research Center, Japan Aerospace Exploration Agency (EORC/JAXA). Thanks to the Climate Prediction Center for providing the station data.

Conflicts of Interest: The authors declare no conflict of interest.

\section{References}

1. Huffman, G.J.; Bolvin, D.T.; Nelkin, E.J.; Wolff, D.B.; Adler, R.F.; Gu, G.; Hong, Y.; Bowman, K.P.; Stocker, E.F. The TRMM Multisatellite Precipitation Analysis (TMPA): Quasi-Global, Multiyear, Combined-Sensor Precipitation Estimates at Fine Scales. J. Hydrometeorol. 2007, 8, 38-55. [CrossRef]

2. Joyce, R.J. CMORPH: A Method that Produces Global Precipitation Estimates from Passive Microwave and Infrared Data at High Spatial and Temporal Resolution. J. Hydrometeorol. 2004, 5, 487-503. [CrossRef] 
3. Xie, P.; Joyce, R.; Wu, S.; Yoo, S.-H.; Yarosh, Y.; Sun, F.; Lin, R. Reprocessed, Bias-Corrected CMORPH Global High-Resolution Precipitation Estimates from 1998. J. Hydrometeorol. 2017, 18, 1617-1641. [CrossRef]

4. Hsu, K.-L.; Gupta, H.V.; Gao, X.; Sorooshian, S. Estimation of physical variables from multichannel remotely sensed imagery using a neural network: Application to rainfall estimation. Water Resour. Res. 1999, 35, 1605-1618. [CrossRef]

5. Behrangi, A.; Hsu, K.-L.; Imam, B.; Sorooshian, S.; Huffman, G.J.; Kuligowski, R.J. PERSIANN-MSA: A Precipitation Estimation Method from Satellite-Based Multispectral Analysis. J. Hydrometeorol. 2009, 10, 1414-1429. [CrossRef]

6. Kubota, T.; Ushio, T.; Shige, S.; Kida, S.; Kachi, M.; Okamoto, K. Verification of High-Resolution Satellite-Based Rainfall Estimates around Japan Using a Gauge-Calibrated Ground-Radar Dataset. J. Meteorol. Soc. Jpn. 2009, 87, 203-222. [CrossRef]

7. Sharifi, E.; Steinacker, R.; Saghafian, B. Assessment of GPM-IMERG and Other Precipitation Products against Gauge Data under Different Topographic and Climatic Conditions in Iran: Preliminary Results. Remote Sens. 2016, 8, 135. [CrossRef]

8. Beria, H.; Nanda, T.; Bisht, D.S.; Chatterjee, C. Does the GPM mission improve the systematic error component in satellite rainfall estimates over TRMM? An evaluation at a pan-India scale. Hydrol. Earth Syst. Sci. 2017, 21,6117-6134. [CrossRef]

9. Kidd, C.; Bauer, P.; Turk, J.; Huffman, G.J.; Joyce, R.; Hsu, K.-L.; Braithwaite, D. Intercomparison of High-Resolution Precipitation Products over Northwest Europe. J. Hydrometeorol. 2012, 13, 67-83. [CrossRef]

10. Ushio, T.; Sasashige, K.; Kubota, T.; Shige, S.; Okamoto, K.; Aonashi, K.; Inoue, T.; Takahashi, N.; Iguchi, T.; Kachi, M.; et al. A Kalman Filter Approach to the Global Satellite Mapping of Precipitation (GSMaP) from Combined Passive Microwave and Infrared Radiometric Data. J. Meteorol. Soc. Jpn. 2009, 87, 137-151. [CrossRef]

11. Tian, Y.; Peters-Lidard, C.D.; Adler, R.F.; Kubota, T.; Ushio, T. Evaluation of GSMaP Precipitation Estimates over the Contiguous United States. J. Hydrometeorol. 2010, 11, 566-574. [CrossRef]

12. Guo, H.; Bao, A.; Ndayisaba, F.; Liu, T.; Kurban, A.; De Maeyer, P. Systematical Evaluation of Satellite Precipitation Estimates Over Central Asia Using an Improved Error-Component Procedure. J. Geophys. Res. Atmos. 2017, 122, 10906-10927. [CrossRef]

13. Prakash, S.; Mitra, A.K.; Pai, D.; AghaKouchak, A. From TRMM to GPM: How well can heavy rainfall be detected from space? Adv. Water Resour. 2016, 88, 1-7. [CrossRef]

14. Tang, G.; Ma, Y.; Long, D.; Zhong, L.; Hong, Y. Evaluation of GPM Day-1 IMERG and TMPA Version-7 legacy products over Mainland China at multiple spatiotemporal scales. J. Hydrol. 2016, 533, 152-167. [CrossRef]

15. Khan, S.; Maggioni, V.; Kirstetter, P.-E. Investigating the Potential of Using Satellite-Based Precipitation Radars as Reference for Evaluating Multisatellite Merged Products. J. Geophys. Res. Atmos. 2018, 123, 8646-8660. [CrossRef]

16. Prakash, S.; Mitra, A.K.; AghaKouchak, A.; Liu, Z.; Norouzi, H.; Pai, D.; Norouzi, H. A preliminary assessment of GPM-based multi-satellite precipitation estimates over a monsoon dominated region. J. Hydrol. 2018, 556, 865-876. [CrossRef]

17. Zhao, H.; Yang, B.; Yang, S.; Huang, Y.; Dong, G.; Bai, J.; Wang, Z. Systematical estimation of GPM-based global satellite mapping of precipitation products over China. Atmos. Res. 2018, 201, 206-217. [CrossRef]

18. Thiemig, V.; Rojas, R.; Zambrano-Bigiarini, M.; Levizzani, V.; De Roo, A. Validation of Satellite-Based Precipitation Products over Sparsely Gauged African River Basins. J. Hydrometeorol. 2012, 13, 1760-1783. [CrossRef]

19. Aslami, F.; Ghorbani, A.; Sobhani, B.; Esmali, A. Comprehensive comparison of daily IMERG and GSMaP satellite precipitation products in Ardabil Province, Iran. Int. J. Remote Sens. 2018, 40, 3139-3153. [CrossRef]

20. Liu,Z.; Liua, Z. Comparison of Integrated Multisatellite Retrievals for GPM (IMERG) and TRMM Multisatellite Precipitation Analysis (TMPA) Monthly Precipitation Products: Initial Results. J. Hydrometeorol. 2016, 17, 777-790. [CrossRef]

21. Behrangi, A.; Wen, Y. On the Spatial and Temporal Sampling Errors of Remotely Sensed Precipitation Products. Remote Sens. 2017, 9, 1127. [CrossRef] 
22. Sahlu, D.; Nikolopoulos, E.I.; Moges, S.A.; Anagnostou, E.N.; Hailu, D. First Evaluation of the Day-1 IMERG over the Upper Blue Nile Basin. J. Hydrometeorol. 2016, 17, 2875-2882. [CrossRef]

23. Oliveira, R.; Maggioni, V.; Vila, D.; Morales, C. Characteristics and Diurnal Cycle of GPM Rainfall Estimates over the Central Amazon Region. Remote Sens. 2016, 8, 544. [CrossRef]

24. Zubieta, R.; Getirana, A.; Espinoza, J.C.; Lavado-Casimiro, W.; Aragon, L. Hydrological modeling of the Peruvian-Ecuadorian Amazon Basin using GPM-IMERG satellite-based precipitation dataset. Hydrol. Earth Syst. Sci. 2017, 21, 3543-3555. [CrossRef]

25. Palomino-Angel, S.; Anaya-Acevedo, J.A.; Botero, B.A. Evaluation of 3B42V7 and IMERG daily-precipitation products for a very high-precipitation region in northwestern South America. Atmos. Res. 2019, 217, 37-48. [CrossRef]

26. Satgé, F.; Xavier, A.; Zolá, R.P.; Hussain, Y.; Timouk, F.; Garnier, J.; Bonnet, M.-P. Comparative Assessments of the Latest GPM Mission's Spatially Enhanced Satellite Rainfall Products over the Main Bolivian Watersheds. Remote Sens. 2017, 9, 369. [CrossRef]

27. Lu, D.; Yong, B. Evaluation and Hydrological Utility of the Latest GPM IMERG V5 and GSMaP V7 Precipitation Products over the Tibetan Plateau. Remote Sens. 2018, 10, 2022. [CrossRef]

28. Tian, Y.; Peters-Lidard, C.D. A global map of uncertainties in satellite-based precipitation measurements. Geophys. Res. Lett. 2010, 37. [CrossRef]

29. Zhao, H.; Yang, S.; You, S.; Huang, Y.; Wang, Q.; Zhou, Q. Comprehensive Evaluation of Two Successive V3 and V4 IMERG Final Run Precipitation Products over Mainland China. Remote Sens. 2017, 10, 34. [CrossRef]

30. Aonashi, K.; Awaka, J.; Hirose, M.; Kozu, T.; Kubota, T.; Liu, G.; Shige, S.; Kida, S.; Seto, S.; Takahashi, N.; et al. GSMaP Passive Microwave Precipitation Retrieval Algorithm: Algorithm Description and Validation. J. Meteorol. Soc. Jpn. 2009, 87, 119-136. [CrossRef]

31. Chen, M.; Shi, W.; Xie, P.; Silva, V.B.S.; Kousky, V.E.; Higgins, R.W.; Janowiak, J.E. Assessing objective techniques for gauge-based analyses of global daily precipitation. J. Geophys. Res. Space Phys. 2008, 113. [CrossRef]

32. Yong, B.; Liu, D.; Gourley, J.J.; Tian, Y.; Huffman, G.J.; Ren, L.; Hong, Y. Global View Of Real-Time Trmm Multisatellite Precipitation Analysis: Implications For Its Successor Global Precipitation Measurement Mission. Bull. Am. Meteorol. Soc. 2015, 96, 283-296. [CrossRef]

33. Beck, H.E.; van Dijk, A.I.; Levizzani, V.; Schellekens, J.; Miralles, D.G.; Martens, B.; de Roo, A. MSWEP: 3-hourly $0.25^{\circ}$ global gridded precipitation (1979-2015) by merging gauge, satellite, and reanalysis data. Hydrol. Earth Syst. Sci. 2017, 21, 589-615. [CrossRef]

34. Sun, Q.; Miao, C.; Duan, Q.; Ashouri, H.; Sorooshian, S.; Hsu, K.-L. A Review of Global Precipitation Data Sets: Data Sources, Estimation, and Intercomparisons. Rev. Geophys. 2018, 56, 79-107. [CrossRef]

35. Ebert, E.E.; Janowiak, J.E.; Kidd, C. Comparison of Near-Real-Time Precipitation Estimates from Satellite Observations and Numerical Models. Bull. Am. Meteorol. Soc. 2007, 88, 47-64. [CrossRef]

36. Liebmann, B.; Allured, D. Daily Precipitation Grids for South America. Bull. Am. Meteorol. Soc. 2005, 86, 1567-1570. [CrossRef]

37. Hobouchian, M.P.; Salio, P.; Skabar, Y.G.; Vila, D.; Garreaud, R. Assessment of satellite precipitation estimates over the slopes of the subtropical Andes. Atmos. Res. 2017, 190, 43-54. [CrossRef]

38. DeMaria, E.M.C.; Rodriguez, D.A.; Ebert, E.E.; Salio, P.; Su, F.; Valdes, J.B. Evaluation of mesoscale convective systems in South America using multiple satellite products and an object-based approach. J. Geophys. Res. Space Phys. 2011, 116, D08103. [CrossRef]

39. Yong, B.; Wang, J.; Ren, L.; You, Y.; Xie, P.; Hong, Y. Evaluating Four Multisatellite Precipitation Estimates over the Diaoyu Islands during Typhoon Seasons. J. Hydrometeorol. 2016, 17, 1623-1641. [CrossRef]

40. Maggioni, V.; Meyers, P.C.; Robinson, M.D. A Review of Merged High-Resolution Satellite Precipitation Product Accuracy during the Tropical Rainfall Measuring Mission (TRMM) Era. J. Hydrometeorol. 2016, 17, 1101-1117. [CrossRef]

41. Bitew, M.M.; Gebremichael, M. Evaluation through Independent Measurements: Complex Terrain and Humid Tropical Region in Ethiopia. In Satellite Rainfall Applications for Surface Hydrology; Springer: Berlin/Heidelberg, Germany, 2010; pp. 205-214. 
42. Liu, Z. Comparison of precipitation estimates between Version 7 3-hourly TRMM Multi-Satellite Precipitation Analysis (TMPA) near-real-time and research products. Atmos. Res. 2015, 153, 119-133. [CrossRef]

43. Gourley, J.J.; Hong, Y.; Flamig, Z.L.; Li, L.; Wang, J. Intercomparison of Rainfall Estimates from Radar, Satellite, Gauge, and Combinations for a Season of Record Rainfall. J. Appl. Meteorol. Clim. 2010, 49, 437-452. [CrossRef] 